\title{
Diagnosis and Distribution of Hard Ticks in Cows in Mosul City-Iraq
}

By

\author{
Hiba Hazim Mahmoud ${ }^{* 1}$ and Eman Daham Hadi Al-Mola ${ }^{* 2}$ \\ ${ }^{* 1,2}$ Department of Veterinary Medicine, University of Mosul, Mosul-Iraq
}

\begin{abstract}
:
The present study included the diagnosis of three species of hard ticks belong to the family Ixodidae parasitizing 72 cows out of a total of 145 cows examined, with a total distribution ratio of $49.6 \%$ in the eastern and western regions of Mosul city. Tick species were diagnosed according to morphological and standard characteristics such as palps, capitulum, coxa, scutum, anus, and spiracles.

Ticks of $H$. anatolicum anatolicum recorded the highest prevalence and distribution ratio in cows of $48.6 \%$, followed by both $B$. annulatus and $R$. turanicus with $34.7 \%, 16.7 \%$ respectively.

As for specifying the patterns of ticks' distribution on cows, it was observed that a pattern of single infestation recorded highest distribution ratio of $51 \%$, followed by a double-infestation of $19.4 \%$, while a mixed infestation pattern recorded lowest ratio of $9.7 \%$. With regard to the distribution of tick species on the body areas per tick species, the results showed the prevalence and distribution of $H$. anatolicum anatolicum tick species on the back was $44.1 \%, B$. anaulatus recorded highest prevalence ratio of $29 \%$ in the ear, while $R$. truanicus recorded highest prevalence in the ear, back, and Axillary of $37.1 \%, 28.5 \%$, and $20 \%$ respectively.

The results concerning the distribution of tick species in each area of body showed the prevalence of $H$. anatolicum anatolicum in the ear area by $51.1 \%$, both H. anatolicum and anatolicum recorded highest prevalence ratio in the tail by $51.6 \%$ and $43.6 \%$ respectively, and highest prevalence of $H$. anatolicum and anatolicum species was found in the back by $72 \%$, while the highest prevalence of B.annaulatus
\end{abstract}


was found in the udder and Axillary of 57.9\% and 56.4\% respectively. Nevertheless, the results illustrated that no significant difference had been found regarding the distribution and prevalence of tick species in the eastern and western regions of the city of Mosul.

\section{Introduction:}

Hard ticks are of ectoparasites belong to family Ixodidae, they cause several health and economic problems in tropical and subtropical regions through bloodsucking and being vectors of many parasitic protozoa, including theileria, babesiosis, and anaplasma, in addition to damaging animal skins during parasitism period (Habeeb et al, 2014; Sebastien et al, 2016). Hard ticks include many genera such as Hyalomma, Rhipicephalus, Boophilus, Ambylomma, Ixodes, and Haemaphysalis (Mohammed, 1996). Several studies have been conducted in various provinces of Iraq on the prevalence, distribution, and classification of hard ticks on domestic animals, including a study carried out by (Robson et al., 1968) in the city of Mosul. They had classified many tick species such as Hyalomma.Spp., Rhipicephalus. Spp., Boophilus. Spp., as they confirmed the presence of these species on domestic animals.

On the other hand, Al Moula (Al Moula, 2001) could classify four genera of hard ticks in the city of Mosul relying on the morphological and standard characteristics such as capitulum, palps, coxa, spiracles, shield, and festoons. In addition to the diagnosis of nine species of ticks belong to four genera, namely Hyalomma with distribution ratio of $46 \%$, Rhipicephalus of $31 \%$, followed by Boophilus and Amblyomma of $61 \%$ and $7 \%$ respectively, as these four genera were found in cows, sheep, goats, dogs, horses, and buffaloes.

Moreover, a survey of hard ticks on cows and sheep was conducted by (Raad ;2012) in southern Baghdad, where three genera were identified and diagnosed, 
namely; Hyalomma. spp with distribution ratio of $70 \%$, and both of Boophilus and Rhiicephalus with distribution ratio of $(5 \%, 25 \%)$ respectively.

Besides, two genera of hard ticks were diagnosed in north, central and southern Baghdad, namely Hyalomma with distribution ratio of $41.7 \%$ and Rhipicephalus with distribution ratio of $3.6 \%$ (Salam et al, 2017). While (Maallh;2019) could diagnosed two cow tick species parasitizing sheep in Najaf, namely Sangusineus Sangusineus Rhipicephalus and Boophilus annulatus with distribution ratio of $17.8 \%, 92.1 \%$ ) respectively.

Several studies have been conducted at the level of Arab homeland and the world, including a study submitted by (Peyvond et al.,2018). As that study was conducted in the central region of Iran where they could diagnose and classify three genera and six species of hard ticks parasitizing sheep, cows, and goats, namely Hyalomma anatolicum anatolicum with distribution ratio of $38.3 \%$, H. asisticum 23.3\%, Hyalomma.spp. 3.4\%, R. Sangusineus Sangusineus 14.9\%, and Haemphysalis salcata 10.9\%. Furthermore, (Apurba et al., 2018) indicated the outbreak and prevalence of hard ticks in cows in western India in the city of Bengal, as both genera of Boophilus and Rhipicephalus were diagnosed with distribution ration of $12.5 \%, 32.2 \%$ respectively.

The goal of this study was to recognize the most important genera and species of hard ticks parasitizing cows in the city of Mosul through microscopy and diagnosing ticks relying on the morphological and standard features of hard tick species, and to study distribution ratio of ticks on cows.

\section{Materials and methods:}

The study was based on examining 145 cows from the eastern and western regions of Mosul city, as 72 cows were found infested with various hard tick species. The observed ticks were collected from different areas of cows' body (back, tail, Axillary, udder, and ears) through placing a cotton swab soaked in ethyl alcohol, 
pulling ticks with forceps, and fixing them in glass bottles containing $70 \%$ of ethyl alcohol or $10 \%$ of formalin for the purpose of classification.

\section{Preparation of ticks for classification:}

Practically, 315 ticks were collected from infested cows, specimens were cleaned up with a fine brush and microscopically examined to remove what might be stuck from host's tissues. The specimens were washed with running water, as the engorged females were placed between two glass slides and slightly pressed to have them flatten. The specimens were put in a potassium hydroxide solution (KOH 10\%) to soften them, and they were transferred to a series of graded alcohols $(50,70,90$, $100 \%$ ) respectively to remove what might be stuck of water, then the specimens were dehydrated by putting them in xylol for a day or more according to the size of tick. Specimens were placed under light and anatomical microscope to measure the length and width of ticks by using Ocular micrometer, those specimens were fixed by Canada balsam, removing air bubbles, and the slide cover was placed, where the slides were dehydrated and labeled (Al Moula,1982; Soulsby, 1982; William, 2001).

\section{Results:}

It turned out, through examining 145 cows, that 72 cows had been infested with various species of ticks in the eastern and western regions of Mosul city. The total number of collected ticks from infested cows was 315 ticks belong to three genera; Hyalomma, Boophilus, and Rhipicephalus. Three tick species, namely $H$. anatolicum anatolicum, B. annulatus, and $R$. turanicus were classified as belonging to these genera. Morphological and standard characteristics were adopted in classifying these species as; H. anatolicum anatolicum which characterized by the palps that consisted of four pieces, the first one is short, the second is long and its length is more than its width, the third one is equal in length and width, and the fourth piece is small, the capitulum is round, the shield's length is equal to its width, 
the spiracles are large and in inverted-commas shape, a coxa in the first pair of legs split into thin external and wide internal spurs.

There are 9-11 festoons, the body bears four pairs of large yellow legs cordoned by brown straps. the anus of a male is characterized by being surrounded by paranal plate, accessory paranal plate, and anal groove that ends at the end of torso. There are sub-anal plates that protrude sometimes out of the body in the form of two small balls among the festoons, image $(1,2,3,4)$.

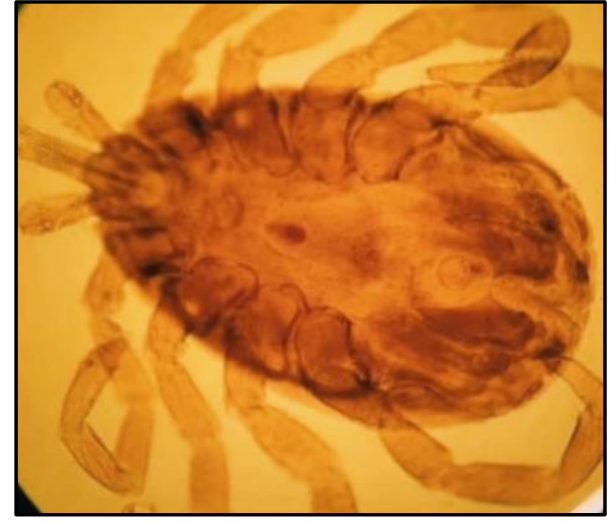

Image (1): Male of a species Hyalomma anatolicum anatolicum

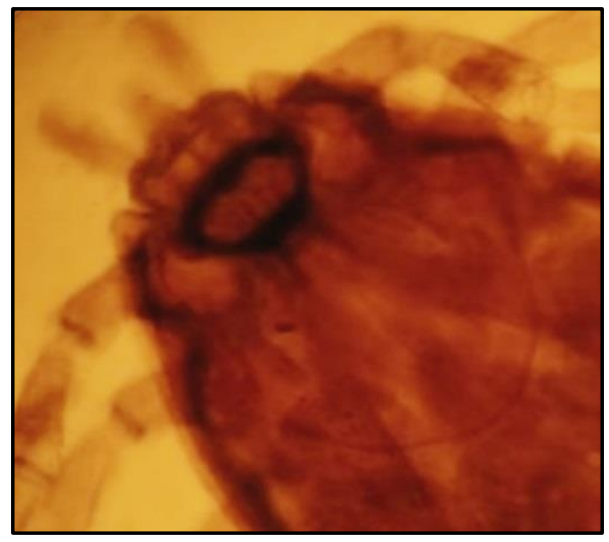

Image (3): Female of Hyalomma anatolicum anatolicum, shows the shield extends to the third pair of legs

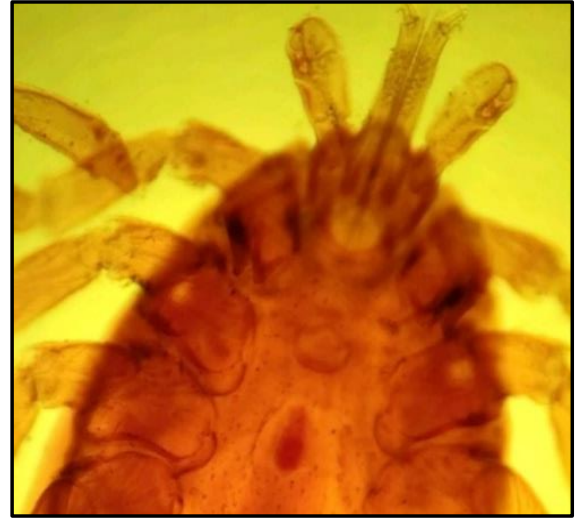

Image (2) Shows the palps, chelicerae. tongue, round capitulum, coxa of the first pair of legs split into two spurs, and eyes sockets on the second pair of legs

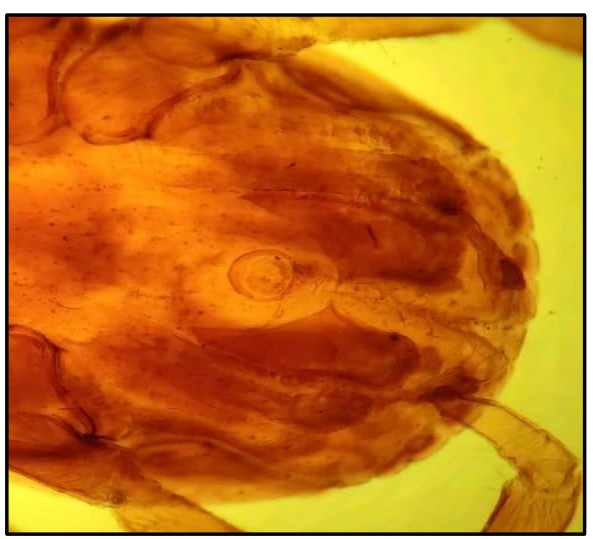

Image (4): Male of Hyalomma anatolicum anatolicum, a spiracle, anus, paranal plate, anal groove, adanal, festoons 
With regard to $B$. annulatus which characterized by; the palps are short, laterally compressed, and consist of four small and short segments with sharp edges. The basis capitulum is hexagonal and seems to be attached to the torso, the shield is heart shaped, the spiracle is oval and sometimes spherical shaped. The coxa of the first pair of legs is V-shaped. It bears four pairs of thin legs, image $(5,6,7)$.

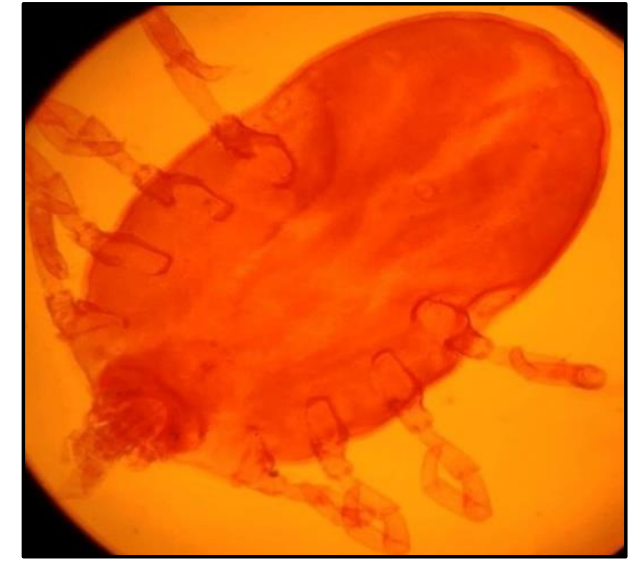

Image (5): Female of Boophilus annulatus

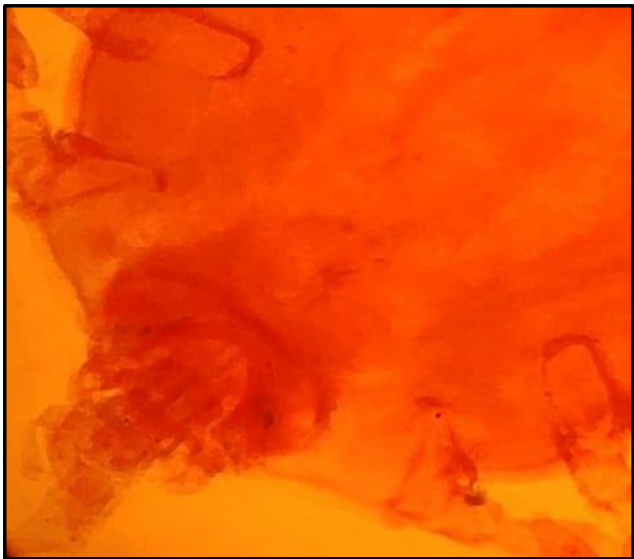

Image (6): A hexagonal capitulum, Vshaped coxa of the first pair of legs

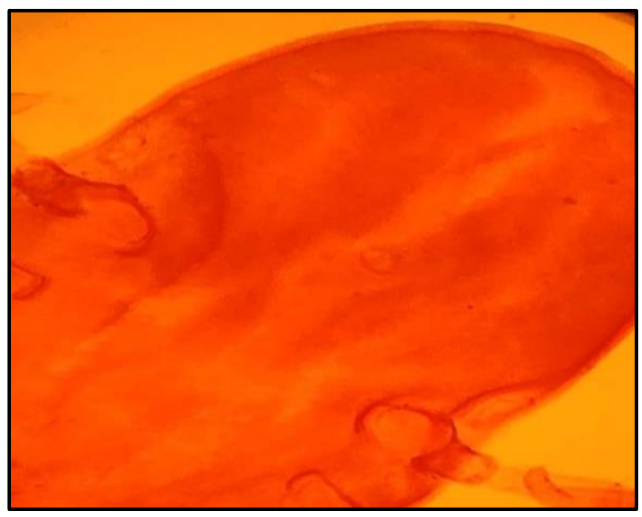

Image (7) A spherical shaped spiracle, the anus has no festoons

A species R.turanicus is characterized by the palps consist of four segments, the second and third segments being equal in length and width, the fourth segment is small. The capitulum is hexagonal and attached to the torso through a clear and protruding a nicking. The shield's length is bigger than its width and extends to before the end of body in males, it has obvious radial ornament called festoons, a 
spiracle is inverted comma shaped, It bears four pairs of clearly large light brown legs, image $(8,9,10,11)$.

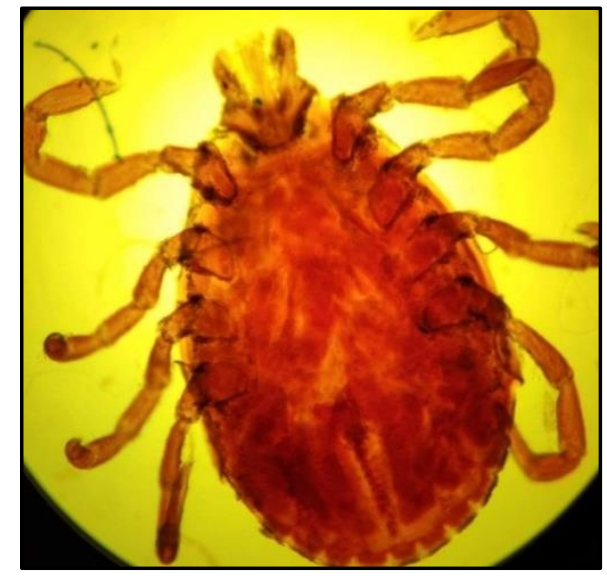

Image (8): Male of phipicephalus turanicus as the scutum extends to before the festoons

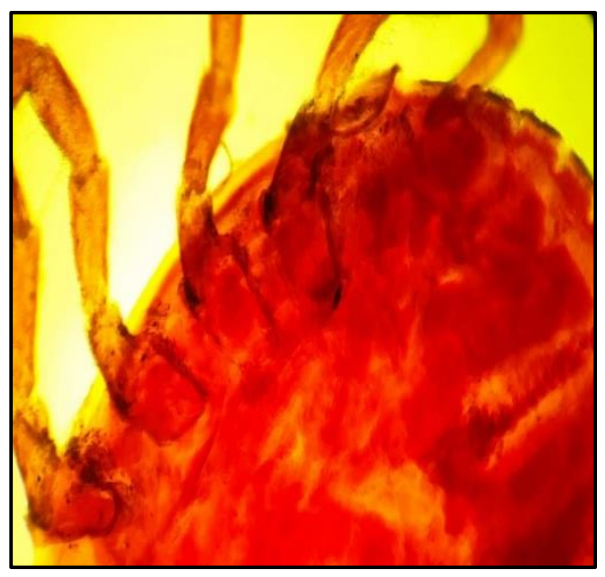

Image (10) Shows legs' coxa, the spiracle is visible with inverted comma shaped, and festoons

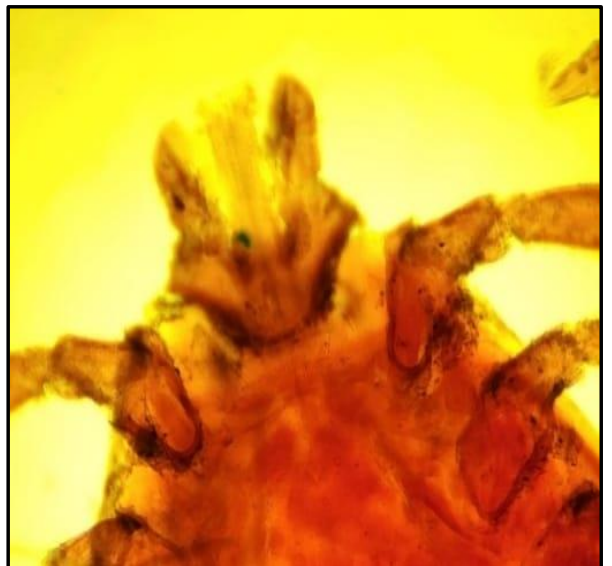

Image (9): Shows the hexagonal capitulum characterized by a protruding nicking, obvious palps and chelicerae, and coxa of the first pair of legs is split into thin external and wide interior spurs

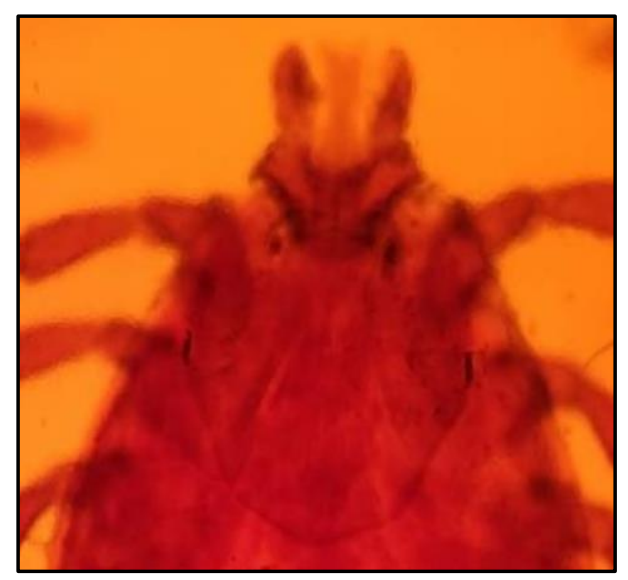

Image (11): Female of phipicephalus turanicus, the scutum extends to coxa of the third pair of legs

Table (1) indicates that significant differences were found at probability level of $(\mathrm{p}<0.05)$ for total, prevalence, and distribution of hard tick species on infested cows. The results revealed that $H$. anatolicum recorded the highest ratio amounted to $54 \%$, while $R$. turanicus recorded the lowest ratio of $11.1 \%$. As for the prevalence and distribution of ticks on cows, $H$. anatolicum anatolicum recorded again the 
highest ratio of prevalence and distribution on cows amounted to $48.6 \%$ and $R$. turanicus recorded lowest ratio of $16.7 \%$.

The results demonstrated the presence of significant differences at probability level of $(\mathrm{p}<0.05)$ to specify distribution patterns of tick species on infested cows. Table (2) illustrates that single infestation recorded highest ratio of prevalence and distribution of $51 \%$, followed by double- infestation of $19.4 \%$, while the mixed infestation recorded the lowest ratio of $9.7 \%$.

Table(A-3) indicates that significant differences were found at probability level of $(\mathrm{p}<0.05)$ for the distribution of tick species among parts of body per tick species. As the results showed the prevalence and distribution of $H$. anatolicum anatolicum on the back by a ratio of $44.1 \%$, followed by the ear and tail areas by a ratio of $27.6 \%$ and $18.8 \%$ respectively, while the prevalence ratio decreased to $5.8 \%$ and $3.5 \%$ in the udder and Axillary respectively. On the other hand, a tick species B. annulatus recorded the highest ratio of prevalence in the ear area of $29 \%$, followed by the tail and Axillary areas by $24.5 \%$ and $20 \%$ respectively, while the lowest ratio of prevalence of $16.3 \%$ and $10 \%$ was in the back and udder respectively. The results showed that $R$. turanicus recorded the highest ratio of prevalence in each of the ear, back, and under armpit amounted to $37.1 \%, 28.5 \%$, and $20 \%$ respectively. The lowest ratio of prevalence was observed in the tail by $18.5 \%$, followed by the udder of $5.7 \%$.

As to the distribution of tick species in each area of body, table (3-B) illustrates the prevalence of $H$. anatolicum anatolicum by $51.1 \%$, folowed by B. annulatus by $34.8 \%$, and then by $R$. turanicus by $14.1 \%$ in the ear area. Both tick species of $H$. anatolicum anatolicum and B. annulatus recorded prevalence ratio in the ear and tail area of $51.6 \%$ and $43.6 \%$ respectively. Furthermore, H. anatolicum anatolicum recorded also highest prevalence ratio in the back by $72 \%$, 
while $B$. annulatus also recorded a high prevalence ratio in the udder and Axillary areas by $57.9 \%$ and $56.4 \%$ respectively.

Table (4) indicates that there is no significant difference in terms of distribution and prevalence of tick species on cows in the eastern and western regions of Mosul. Table (5) indicates the morphological measurements of hard tick species body parts.

Table (1): Illustrates total, prevalence, and distribution of hard tick species in infested cows

Types and numbers of cows - there is a significant difference (the different letters meant to two different ratios

\begin{tabular}{||c|c|c|c||}
\hline Type & No & \% & Sig \\
\hline H & 170 & 54.0 & A \\
\hline B & 110 & 34.9 & B \\
\hline R & 35 & 11.1 & C \\
\hline total & 315 & 100.0 & \\
\hline \multicolumn{4}{|l}{} \\
\hline cows & No & $\%$ & Sig \\
\hline H & 35 & 48.6 & A \\
\hline B & 25 & 34.7 & AB \\
\hline R & 12 & 16.7 & B \\
\hline total & 72 & 100.0 & \\
\hline \hline
\end{tabular}

Table (2): Illustrates the patterns of hard tick species distribution on infested cows.

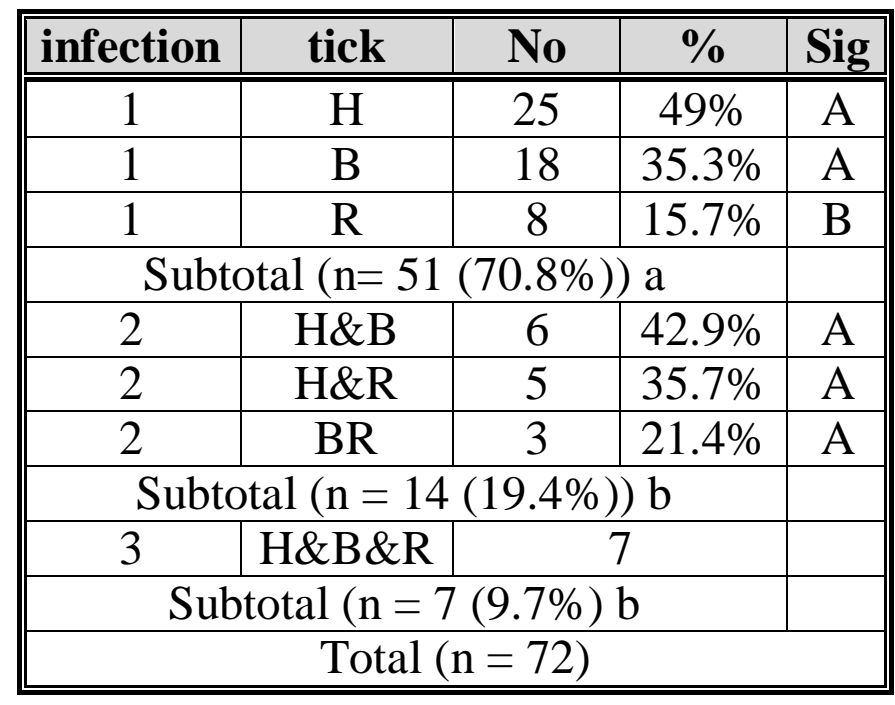


Table (3-A): Demonstrates the distribution of tick species among body areas for each tick species

Body area (A) Differences among body areas for each tick species.

\begin{tabular}{|c|c|c|c|c|c|c||}
\hline Type & total & ear & tail & back & udder & Axillary \\
\hline \hline \multirow{3}{*}{$\mathbf{H}$} & \multirow{2}{*}{$\mathbf{1 7 0}$} & 47 & 32 & 75 & 6 & 10 \\
& & $(27.6 \%)$ & $(18.8 \%)$ & $(44.1 \%)$ & $(3.5 \%)$ & $(5.8 \%)$ \\
& & $\mathrm{B}$ & $\mathrm{C}$ & $\mathrm{A}$ & $\mathrm{D}$ & $\mathrm{D}$ \\
\hline & & 32 & 27 & 18 & 11 & 22 \\
$\mathbf{B}$ & \multirow{2}{110}{} & $(29 \%)$ & $(24.5 \%)$ & $(16.3 \%)$ & $(10 \%)$ & $(20 \%)$ \\
& & $\mathrm{A}$ & $\mathrm{AB}$ & $\mathrm{BC}$ & $\mathrm{C}$ & $\mathrm{AB}$ \\
\hline & & 13 & 3 & 10 & 2 & 7 \\
$\mathbf{R}$ & \multirow{3}{*}{35} & $(37.1 \%)$ & $(18.5 \%)$ & $(28.5 \%)$ & $(5.7 \%)$ & $(20 \%)$ \\
& & $\mathrm{A}$ & $\mathrm{B}$ & $\mathrm{A}$ & $\mathrm{C}$ & $\mathrm{AC}$ \\
\hline
\end{tabular}

Table (3-B): Shows the distribution of tick species in each area of body

Body area (B) differences between tick species in each area of body.

\begin{tabular}{|c|c|c|c|c|c||}
\hline Type & ear & tail & back & udder & Axillary \\
\hline \hline & 47 & 32 & 75 & 6 & 10 \\
H & $(51.1 \%)$ & $(51.6 \%)$ & $(72.8 \%)$ & $(31.6 \%)$ & $(25.6 \%)$ \\
& $\mathrm{A}$ & $\mathrm{A}$ & $\mathrm{A}$ & $\mathrm{AB}$ & $\mathrm{B}$ \\
\hline & 32 & 27 & 18 & 11 & 22 \\
$\mathbf{B}$ & $(34.8 \%)$ & $(43.6 \%)$ & $(17.5 \%)$ & $(57.9 \%)$ & $(56.4 \%)$ \\
& $\mathrm{B}$ & $\mathrm{A}$ & $\mathrm{B}$ & $\mathrm{A}$ & $\mathrm{A}$ \\
\hline & 13 & 3 & 10 & 2 & 7 \\
$\mathbf{R}$ & $(14.1 \%)$ & $(4.8 \%)$ & $(9.7 \%)$ & $(10.5 \%)$ & $(18 \%)$ \\
& $\mathrm{C}$ & $\mathrm{B}$ & $\mathrm{B}$ & $\mathrm{B}$ & $\mathrm{B}$ \\
\hline Total & 92 & 62 & 103 & 19 & 39 \\
\hline \hline
\end{tabular}




\section{Table (4): illustrates the distribution of hard tick species on infested cows in} the eastern and western regions of Mosul

Area inside Mosul- there is no significant difference.

\begin{tabular}{||c|c|c|c|c|c|c||}
\hline & \multicolumn{2}{|c|}{ East } & & \multicolumn{2}{c|}{ West } & \\
\hline Type & No & Percent & Sig & yes & Percent & Sig \\
\hline H & 97 & 57.1 & A & 73 & 42.9 & A \\
\hline B & 52 & 47.3 & A & 58 & 52.7 & A \\
\hline R & 22 & 62.9 & A & 13 & 37.1 & A \\
\hline total & 171 & 167.2 & & 144 & 132.8 & \\
\hline
\end{tabular}

Table (5): Shows the morphological measurements for tick species body parts (unit of measure is $\mathbf{m m}$ )

\begin{tabular}{|c|c|c|c|c|c|c|c|c|c|c|c|}
\hline Tick species & $\begin{array}{c}\text { Shield } \\
\text { length }\end{array}$ & $\begin{array}{c}\text { Shield } \\
\text { width }\end{array}$ & $\begin{array}{c}\text { Spiracle plate } \\
\text { length }\end{array}$ & $\begin{array}{c}\text { Spiracle } \\
\text { plate } \\
\text { width }\end{array}$ & $\begin{array}{c}\text { Anal } \\
\text { length }\end{array}$ & $\begin{array}{c}\text { Anal } \\
\text { width }\end{array}$ & $\begin{array}{c}\text { model } \\
\text { length }\end{array}$ & $\begin{array}{c}\text { model } \\
\text { width }\end{array}$ & $\begin{array}{c}\text { Leg's } \\
\text { length }\end{array}$ & $\begin{array}{c}\text { Capitulium } \\
\text { length }\end{array}$ & $\begin{array}{c}\text { Capitulium } \\
\text { width }\end{array}$ \\
\hline $\begin{array}{c}\text { Booophilus } \\
\text { annulatus }\end{array}$ & $0.60 \mathrm{~mm}$ & 0.60 & 0.42 & 0.25 & 0.25 & 0.14 & $4.13 \mathrm{~mm}$ & 2.20 & 1.81 & 053 & 0.53 \\
\hline $\begin{array}{c}\text { H.anatolicum } \\
\text { anatolicum }\end{array}$ & 2.71 & 2.02 & 0.55 & 0.18 & 0.19 & 0.18 & 4.18 & 2.05 & 2.59 & 0.89 & 0.63 \\
\hline $\begin{array}{c}\text { Rhipicephauls } \\
\text { turanicus }\end{array}$ & 1.76 & 1.29 & 0.57 & 0.22 & 0.16 & 0.08 & 3.31 & 1.60 & 1.83 & 0.49 & 0.48 \\
\hline
\end{tabular}

\section{Discussion:}

Three hard tick species were diagnosed in this study belonging to three genera, namely Hyalomma, Rhipicephalus, and Boophilus. Results were in line with what (Raad,2012; Khalid, J., and Lokman T., 2019) concluded, as they managed to diagnose three genera of hard ticks in the north and south of Iraq. Nevertheless, the results weren't in conformity with what (Al Moula, 2001) concluded, as he diagnosed four genera in the city of Mosul parasitizing cows, sheep, goats, camals, horses, and dogs, namely Hyalomma, Boophilus, Rhicipephalus, and Ambylomma. While only three genera were diagnosed in this study, and this can be attributed to the current 
study was limited to cows only unlike the previous study which was conducted on six animals.

Ticks transmit several parasitic protozoa, including Theileria, Anaplasma, Babesiosis, Trypanosoma, and others to animals, among them cows. When ticks feed on the blood of animals, this leads to transmit the protozoa in ticks' salivary glands where they reproduce in red blood corpuscles and lymph glands of cows which causes a lot of damages, including reduced milk production, enlarged lymph nodes (lymphadenopathy), bloody urine (hematuria), underweight, and loss of appetite (anorexia) (Ramadan, et al., 2016; Omid, et al., 2018).

Results of the present study have showed that 72 cows were infested, by a total distribution ratio of $49.6 \%$, as Hyalomma anatolicum anatolicum recorded highest distribution ratio of $48.6 \%$. The results of current study were in conformity with what (Al Moula, 2001) observed, as he recorded almost similar distribution ratio of $46 \%$. The prevalence and presence of this species at a high ratio might be attributed to its adaptation to the environmental conditions such as temperatures suitable for this species to be adaptive, and lack of cleanliness of stables that help the existence of intermediate hosts to complete the life cycle of ticks, as well as the availability of grasses and herbs considered as a suitable shelter for ticks' presence and reproduction.

The present study highlighted the diagnosis of three tick species parasitizing cows. Morphological features were adopted in classifying species, one of which is H. anatolicum anatolicum which characterized by; the length of second palp is more than its width, the third one is equal in length and width, the capitulum is round, the torso is thin at the top and round at the bottom, the shield is equal in length and width, the coxa of the first pair of legs is split into thin external and wide internal spurs, and the spiracle is inverted comma shaped. While the male is characterized by the anus which's surrounded by; paranal plate which is large, accessory paranal 
plate, and anal groove which ends with end of the torso. The description of the current model is compatible with a species above, it can be concluded that the specifications of model is close to that of $H$. anatolicum anatolicum. The results are in conformity with what (Al Moula, 2001) mentioned, as he confirmed the prevalence of this species in six domestic animals in the governorate of Nineveh.

B. annulatus is characterized by significant features; the palps are short and compressed from side and consist of four segments, the first one is attached to the body, the second is almost equal in length and width, and the third and fourth are small and short, the coxa of the first pair of legs is V-shaped with a spur at its end, the capitulum is hexagonal and appears to be attached to the torso, the shield in females is heart-shaped, the spiracle is oval and sometimes spherical. it turns out that the current model is similar to the description above and thus it's in conformity with what was mentioned in previous studies (Leiper,1957). This species was observed by (Mallhi, 2019) in several animals, among them were cows.

A species Rhipicephalus turanicus is characterized by; the second and third segments of palps are equal in length and width, the fourth one is small, the capitulum is hexagonal and attached to the torso by a clear and protruding nicking . The shield's length is larger than its width, the spiracle is inverted comma shaped, and the legs' coxa are graded in size where the first one is small and the fourth is bigger than all. The current study demonstrated that the description of model is similar to the model above. The results were in conformity with what (Raad,2012; Apurba et al., 2018) mentioned, as they managed to diagnose ticks of cows in southern Baghdad and western India in the city of Bengal.

The results have demonstrated that a pattern of single infestation had recorded highest distribution ratio of $51 \%$ by $H$. anatolicum anatolicum with significant differences in both patterns of double and mixed infestations at a significant level of $(p<0.05)$. This can be attributed to the adaptation of 
H. anatolicum anatolicum to parasitize on cows and being a dual-host tick, which needs two hosts to complete its life cycle, so it's hard to eradicate.

It was observed, pertaining distribution of ticks on animal body areas, that $H$. anatolicum anatolicum recorded highest distribution ratio of $44.1 \%$ on the back, and this due to the expansion of ticks' parasitism region. As a species B. annulatus recorded highest prevalence ratio in the ear area of $29 \%$, while $R$. turanicus recorded highest prevalence ratio in the ear, back, and Axillary of $37.1 \%, 28.5 \%$, and $20 \%$ respectively. As for distribution of tick species in each area of body, results showed that a ratio of prevalence and distribution of $H$. anatolicum anatolicum and $B$. annulatus was obvious in the tail area by $51.6 \%$ and $43.6 \%$ respectively, while the ratio of prevalence of $H$. anatolicum anatolicum was in the back area by $72 \%$, and prevalence of B. annulatus was in the udder and Axillary by $57.9 \%$ and $56.4 \%$ respectively.

The current results have been in conformity with the findings of (Al Moula,2011), where he illustrated the distribution and prevalence of $H$. anatolicum anatolicum, B. annulatus, and $R$. turanicus on animal body areas. The reason for ticks choosing the back area can be attributed to the lack of movement and expansion of back area that prevents animal from itching and removing the ticks. Perhaps the ticks have the nature of climbing onto the top of grasses waiting for a suitable animal to climb on its back. Or it can be attributed to the fact that female ticks may secrete a specific pheromone that attracts males for mating, or perhaps secreting a pheromone to attract stages of the species' life cycle, which leads to prevalence of tick species on the back of animal, including cows. As for choosing the ear area, the reason may due to the abundance of blood vessels in that area close to the skin layer. As for choosing the tail area, it can be attributed to the availability of protection, darkness, and heat, and this important to protect ticks from being exposed to sunlight or predation. While the reason for choosing the udder is due to its temperature which 
is higher than the rest of the body especially in the winter when the surrounding temperature is low. To the contrary, Axillary area is deemed the least suitable area for parasitism due to animal's constant itching which drops ticks off the body to the ground prior to feeding on animals' blood (Bigya et al., 2018).

\section{References :}

1. Habeeb, W. K. S., Najim, A. H. and Mohammed, K. M., 2014. Ixodid ticks diversity in the middle and south of Iraq. International journal of Recent Scientific Research; 5(9): pp. 1518-1523.

2. Sebastien, G. A., Frederic, S., Renoud, L., Jerome, B., Jean, F. A., Sylrain, M., Oscar, M. and Gerrit, U., 2016. Ticks (Acari: Ixodida) infesting cattle and some other domestic and wild hosts on the French Mediterranean island of Corsica. Parasites and Vectors; 9: 582.

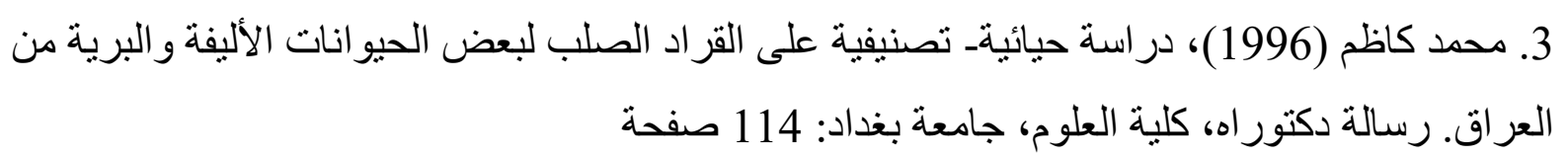

4. Robson, J., Robb, J. M. and Hawa, N. J., 1968. Ticks (Ixodoidea) of domestic animals in Iraq part 4. A comparison of infestations in winter and early summer in the Liwa of Mosul. Journal of Medical Entomology; 5(2): 261-264.

5. Raad, H. H., 2012. Tick distribution and infestation among sheep and cattle in Baghdad's south suburb. Kufa Journal for Veterinary Medical Science; 3(1).

6. Salam, M. H. S., Salah, F. A., and Mohammed, K. M., 2017. Ixodid ticks diversity and seasonal dynamic on cattle in north, Middle and South of Iraq. International Journal of the Systematic and applied Acarology Society; 22 (10).

7. Maallh, T. H., 2019. Morphological study of the cattle ticks (A cari Txodidae) in festing on sheep in Alnnajaf province-Iraq. Materials Science and Engineering; 571. 
8. Peyvand, B., Hasan, B., Sadegh, C., Hamid, B., Mosoud, G., Siavash, J., Faezeh, F., and Zakkyeh, T., 2018. Hyalomma anatolicum as the main infesting tick in an important livestock rearing region, central area of Iran. Iran Journal Public Health; 47(5): pp. 742-749.

9. Apurba, D., Soumitra, P., Ruman, J., Surajit, B., Subhas, C. M., and Partha, S. J., 2018. Prevalence of hard tick infestations in cattle of west Bengal, Inida. Biological Rhythm Research; 49: 655-662.

10. Soulsby, E. J. K., 1982, Helminthes, Arthropods, and Protozoan of domestic animals. 8thed, Bailiere, Tindal, London; 767.

11. William, J. F., 2001. Veterinary parasitology. 5thed. Blackwell publishing. Lowa state University Press. 104-106.

12- المولى، ايمان دحام (2001)، دراسة تصنيفية لأنو اع القراد المتطفل على بعض اللبائن في محافظة ayalomma anatolicum نينوى والتغيرات النسيجية الناتجة من تطفل القراد الاناضولي anatolicum . رسالة ماجستير، كلية العلوم، جامعة الموصل: 108 صفحات.

13. Khalid, J. A., and Lokman, T. O. B., 2019. Prevalence rate of ixodia ticks in Equids and some nearby from animals in Erbil governorate, North of Iraq. Bas. J. Vet; 18 (1).

14. Ramadan, M. Y., Elakabawy, L. M., Elmdaway, R. S., and Kama, M. M., 2016. Prevalence of hard tick infesting cattle with a special reference to microscopic and molecular early diagnosis of tick born piroplasms. Benha Veterinary Medical Journal; 30(2): 51-60.

15. Omid, B., Ahmad, A. H., Mohamad, K., Faezeh, F., Mojaba, B. M., Sajere, G., Siavash, J., Hamideh, E., Hassan, V., and Zakkeh, T., 2018. Tick ectoparasites of animals in Borderline of Iran-Iraq and their role on disease transmission. Journal Arthropod-Borne Disease; 12(3): 252-261.

16. Loipor, J. w. G., 1957. Report to the government of Iraq on animal parasites and their control. FAO. Rome. 1-28. 
17. Bigya , D., Sular, S., Krishna, K. and Rameshwor, P., 2018.Distribution of the cattle ticks from mid hills to plains of Nepal. Journal of Agriculture and Natural Resources; 1(1): 197-205. 